Article

\title{
Health Behaviors of Student Community Research Partners When Designing and Implementing a Healthy Lifestyle Intervention on College Campuses
}

\author{
Makenzie L. Barr ${ }^{1}{ }^{(0}$, Sarah E. Colby ${ }^{2}{ }^{\infty}$, Kristin Riggsbee ${ }^{2}$, Krista Leischner ${ }^{3}$, \\ Anne E. Mathews ${ }^{4}\left(\mathbb{D}\right.$, Melissa J. Vilaro ${ }^{4}$, Kendra K. Kattelmann ${ }^{3}(\mathbb{D})$ and Melissa D. Olfert ${ }^{1, *}$ \\ 1 Division of Animal and Nutritional Sciences, School of Agriculture, Davis College of Agriculture, \\ Natural Resources and Design, West Virginia University, 1194 Evansdale Drive, \\ G25 Agriculture Sciences Building, Morgantown, WV 26506, USA; mbarr6@mix.wvu.edu \\ 2 Department of Nutrition, The University of Tennessee, 1215 W. Cumberland Avenue, \\ 229 Jessie Harris Building, Knoxville, TN 37996-1920, USA; scolby1@utk.edu (S.E.C.); \\ kristin.riggsbee@gmail.com (K.R.) \\ 3 Department of Health and Nutritional Sciences, South Dakota State University, HNS Department, \\ Rotunda Lane, Wagner 425, Box 2203, Brookings, SD 57007, USA; krista.leischner@jacks.sdstate.edu (K.L.); \\ kendra.kattelmann@sdstate.edu (K.K.K.) \\ 4 Food Science and Human Nutrition Department, University of Florida, 572 Newell Dr., 359 FSHN Building, \\ P.O. Box 110370, Gainesville, FL 32611-0370, USA; anne.mathews@ufl.edu (A.E.M.); \\ mgraveley@ufl.edu (M.J.V.) \\ * Correspondence: melissa.olfert@mail.wvu.edu
}

Received: 8 October 2018; Accepted: 24 October 2018; Published: 26 October 2018

\begin{abstract}
Few studies work with college students as equal partners in all aspects of Community-Based Participatory Research (CBPR) and even less evaluate behaviors of those college partners. The current study aimed to examine health behaviors of students by designing and implementing a peer-led, social marketing campaign (Get Fruved) to promote healthier lifestyles on their campuses. Enrolled students $(n=376)$ were trained to either design and implement a health promotion intervention (Social Marketing and Environmental Interventionists; SMEI, $\mathrm{n}=78$ ), be peer mentors (PM; $\mathrm{n}=205$ ), or serve as control participants $(\mathrm{n}=93)$. Students' behaviors (dietary, activity, and stress) and anthropometrics were assessed at baseline, 6 months, and 12 months. The population was predominately Caucasian, female, and between 19 and 20 years old. On average, fruit and vegetable consumption slightly decreased across all time points for each group with control at a larger decline. Students International Physical Activity Questionnaire (IPAQ) scores showed students met recommended amounts of activity throughout the intervention, with males reporting higher activity levels. Cohen's Perceived Stress Scale (PSS) analyses indicated 19 year olds had higher stress along with females had higher than males. Students involved in a CBPR approach to be trained, design, and implement a lifestyle intervention can achieve maintenance of health behaviors throughout a college year when compared to control students.
\end{abstract}

Keywords: CBPR; college students; health; behavior; interventionists

\section{Background}

Community-Based Participatory Research (CBPR) brings together the efforts of researchers and community members as equal partners in developing an intervention for that community $[1,2]$. An important aspect of CBPR is working with partners who are invested in the research and want to make a difference in their community. One form of CBPR is for researchers to team with college 
students to conduct an intervention on a college campus. Various research programs have used college students either to gain insight into a collegiate population, develop and/or implement an intervention, or to assist with data collection [2-18]. However, few of these studies have worked with students as equal partners in all aspects of a lifestyle intervention research process, as is called for in CBPR, and fewer still have evaluated the health impacts made on the interventionists. Previous literature has only involved student partners in aspects of intervention development such as focus group only, data collection only, or data analyses only. Our project examined the use of CBPR student partners in training on the subject, development of the intervention, marketing and events, as well as dissemination of the intervention.

One field that offers significant potential for a successful CBPR college campus intervention is in the areas of health and wellness. College students live in an independent environment on campus which has been noted to be tied with poor dietary, activity, sleep, and stress behaviors and is a target for health promotion interventions [19-23]. However, identifying students interested in health-related fields could serve as successful collaborators on leading CBPR healthy lifestyle interventions for their peers $[2,4,8,15,16,24]$. Currently, there is little research investigating behavior change in these community interventionists who design and implement a CBPR intervention. Furthermore, participating in the process of designing and conducting a healthy lifestyle intervention could improve the interventionists' health-related behaviors and attitudes. However, to date, no study has investigated the changes among college student research partners in a CBPR healthy lifestyle intervention compared to control students who were not engaged in the intervention's design and implementation.

\section{Project Overview}

Students described in this manuscript were partners in the development of the 'Get Fruved' study (short for FRUits and VEgtables). Get Fruved was a multi-state, peer-led, social marketing, and environmental change obesity prevention intervention funded by the United States Department of Agriculture. The project involved four control (Syracuse University, Kansas State University, University of Maine, and Auburn University) and four intervention universities (University of Tennessee, South Dakota State University, University of Florida, and West Virginia University) in the United States. Get Fruved used CBPR to increase healthy lifestyles among the college population, specifically, first-year students at higher risk for weight gain and other unhealthy lifestyle behaviors [25].

Students interested in healthy living at each of the four intervention university campuses were recruited using various methods [26]. A recruitment goal of 30 Social Marketing and Environmental Intervention students (SMEI students) and 120 Peer Mentors for Health (PM) per intervention university was set. SMEI and PM were recruited throughout fall semester of 2014 to enroll in a university course (SMEI: 3 credit hours; PM: 1 credit hour) during spring 2015. Recruitment was performed through campus-wide announcements, social media, flyers, word of mouth, informational meetings, and campus informational booths. In addition, recruiters emailed student organizations, spoke to 100/200 level courses, designed short recruitment videos, and reached out to the universities' health organizations. Upperclassmen students (students enrolled as sophomore-senior status or had 1-3 years of experience on campus) were preferentially recruited because they were familiar with the territory, were on campus the upcoming year to help implement the intervention, and understood the need for a lifestyle intervention at their university. These upperclassmen CBPR partner students had the ability to decide what program (SMEI or PM) they were interested in taking.

During the 15-week course, SMEI students were trained to develop a peer-led social marketing campaign intervention focused on three main topic areas: diet, physical activity, and stress management [27]. Within Get Fruved, these areas were targeted as specific zones of healthy living that can impact well-being long term. An important aspect of the training program included SMEI students auditing the healthfulness of their environment. From this audit and awareness of their campus, teams were formed to design a week of intervention events for the Fruved intervention toolkit. 
During this semester, PM students were simultaneously trained to mentor incoming first year students on the three main umbrella topic areas as well as aspects of the campus including residence life and financial help, leadership, communication, counseling and behavior change, crisis management, and conflict resolution. In this Fruved intervention feasibility pilot year, PMs would be matched to incoming first-year Fruved students and encourage them to make healthy choices, and attend the SMEI students Fruved events, in the frequency and mode (texting, calling, meetings, email, or other) by which their mentee student chose. Two of the control universities (Syracuse University and University of Maine) recruited students to serve as controls. The multi-state umbrella Institutional Review Board at University of Tennessee, Knoxville, approved the study protocol for University of Tennessee, West Virginia University, and South Dakota State University (IRB approval \#14-09366 B-XP). The University of Florida IRB approved the same strategies for activities at the University of Florida (IRB approval \#2014-U-0547FRUVED). The IRB approved study procedures for the control universities, Syracuse University and the University of Maine (\#14-175 and \#2014-06-21, respectively). This study was prospectively registered on clinicaltrials.gov, NCT02941497.

\section{Purpose}

The purpose of this article is to describe changes in self-reported behaviors of SMEI and PM after training, designing, and implementing the Get Fruved pilot intervention [27] compared to control students. To the best of our knowledge, this is the first study assessing the behavior change of young adult community partners across the course of designing and implementing a health promotion intervention for their peers.

\section{Methods}

\subsection{Participants}

In fall of 2014, intervention and control students from 8 universities were recruited to be enrolled in the Get Fruved pilot project [26]. Inclusion criteria required participants were at least 18 years of age and upperclassmen with familiarity of their campus and understanding of the needs of the campus community. These criteria were in place to ensure that these students could inform and design an appropriate intervention that is feasible on their campus by having been on campus for at least one year. Control students were recruited through professors, listservs, flyers, and announcements on campus to serve as a Get Fruved control participant and provide data with the understanding of being compensated monetarily for their time. Control students did not complete the training course. All student participants completed health behavior surveys and anthropometric assessments prior to designing the intervention in spring 2015 (baseline), after designing the intervention in fall 2015 (6-months), and after implementation of the first year of the Get Fruved intervention in spring 2016 (12-months). All control and intervention students were invited to return for a follow-up assessment.

\subsection{Outcome Measures}

Trained researchers performed anthropometric measures at each assessment. Height was measured by stadiometer (Heightonic digital stadiometer; Issaquah, WA, USA) with the participant standing, facing forward without shoes, including height. Weight was taken without shoes and with light clothing via digital scale (Electronic Tanita scale; Arlington Heights, IL, USA). Body Mass Index (BMI) was calculated as weight in kilograms divided by height in meters squared. Waist, hip, and neck circumferences were taken while the participant was minimally clothed via Gulick meter (North Coast Medical Gulick tape measure; Gilroy, CA, USA). Waist measurement was taken at the midpoint between the lower margin of the last palpable rib and the top of the iliac crest; hip circumference was taken at the largest area of the hips, and neck circumference was taken at the Adam's apple area of the neck, indicated by a swallowing motion of the participant. Blood pressures were taken in a seated resting position with an automated cuff (Omron HEM 907 XL Intellisense Prof. Digital BP monitor; 
Kyoto, Japan) that measured twice and averaged [28,29]. All measures were taken twice and averaged. Repeated measures were taken a third time if initial measures had a range larger than $0.2 \mathrm{~kg}$ for weight, $0.2 \mathrm{~cm}$ for height, and $1.0 \mathrm{~cm}$ for waist, hip, and neck circumference. Values were averaged for analysis.

Student participants completed self-reported behavioral surveys, including the National Cancer Institute's Fruit and Vegetable Screener (NCI FV) [30], International Physical Activity Questionnaire (IPAQ) [31], and Cohen's Perceived Stress Scale (PSS) [32]. As the three main foci of the intervention were diet, physical activity, and stress management, these tools were used as outcome measures. The validated NCI FV screener tool identifies 19 self-reported questions on daily fruit and vegetable intake (servings/day). Questions asked students' type and amount of fruit and vegetable consumption during the past month (i.e., "Each time you ate lettuce salad, how much did you usually eat?"). The short-form IPAQ is a validated questionnaire to score physical activity metabolic equivalency tasks in minutes/week (METs). The tool is comprised of six self-reported items of type (light, moderate or vigorous), frequency in days, and duration in minutes of physical activity preformed (i.e., "During the last 7 days, on how many days did you do vigorous physical activities like heavy lifting, digging, aerobics, or fast bicycling?", "How much time did you usually spend doing vigorous physical activities on one of those days?"). The validated PSS scores perceived stress with 14 self-reported questions on a scale of $0-56$. Items include questions regarding stress in the past month (i.e., "in the last month, how often have you felt nervous or stressed?").

\subsection{Statistical Methods}

All analyses were conducted using SAS (SAS ${ }^{\circledR}$, Version 9.3) [33] and JMP (JMP ${ }^{\circledR}$, Version Pro 11) [34]. An a priori sample size analysis to detect a medium effect size (0.25), 0.05 alpha value among 3 groups with 5 measures and a power of $80 \%$, total sample size was 96 participants which was captured within this cohort. Demographic data are reported in frequencies and percentages and group differences at baseline (SMEI, PM, and control) were analyzed with chi-square or Fisher's exact tests with alpha value set to 0.05 . Outliers removed prior to analysis $(n=15)$. Descriptive statistics were run on baseline anthropometric measures; group differences of behavioral scores were tested via analysis of variance (ANOVA) for initial analysis. Finally, descriptive statistics were run on all outcomes at baseline and at the 6-month and 12-month follow-ups. All outcome distributions were examined and transformed as necessary, which included cubed root transformation to NCI FV and IPAQ outcomes in order to improve normality; group differences on the transformed data were tested via ANOVA analysis.

A series of mixed regression models were used to assess the cubed root transformed NCI FV and IPAQ outcomes, and the PSS behaviors in group, over time, and group by time interaction. To fit the flexibility of the means, individual variances and covariances of the data, as well as both fixed and random effects within each model, mixed linear models were used [35,36]. Covariate inclusion was decided a priori by selecting significant bivariate demographics for any of the outcomes and was consistently entered into all models. The best fitting model was determined using Akaike Information Criterion (AIC) and other goodness of fit indices. Null Model Likelihood Ratio chi-squared test (LRT) reported for model fit of covariance structure. Time was treated as a continuous variable in all models. The best fitting models for each PSS and FV included only a repeated statement of time, using an autoregressive (AR1) covariance structure, correcting for the degrees of freedom using Kenward-Roger method, and REML estimation, with student ID as the subject repeated variable. Best fitting model for IPAQ also included only a repeated statement of time, using an unstructured covariance structure, again correcting for the degrees of freedom using Kenward-Roger method, and REML estimation, with student ID as the subject repeated variable. For all models, pairwise comparisons with post hoc Tukey adjustment were performed for significant adjusted mean differences by group. Missing data was assumed to missing at random and pairwise deletion was utilized. 


\section{Results}

The population was predominately Caucasian $(p=0.002)$, female $(p<0.0001)$, and between 19 and 20 years of age $(p=0.0007)$. Table 1 outlines the demographic differences between SMEI, PM, and Control groups. At baseline, weight, BMI, and hip, waist, and neck circumference were significantly different between PM and Control (all $p$ 's $<0.01$ ) while waist and neck circumference were significantly different between SMEI and control $(p<0.001)$ (Table 1$)$. At 12-month assessments (data not shown), significance only remained between control and PM waist circumference $(p=0.0096)$ and neck circumference $(p=0.0004)$. Further, although no differences were seen at baseline, significant differences were seen at 12-months between control and SMEI systolic $(p=0.011)$ and diastolic $(p=0.026)$ blood pressures and control and PM systolic $(p=0.002)$ and diastolic $(p=0.017)$ blood pressures.

Table 1. Baseline demographics and anthropometrics of Social Marketing and Environmental Interventionists (SMEI), peer mentors (PM), and control. GPA: Grade point average; BMI: Body Mass Index.

\begin{tabular}{|c|c|c|c|c|c|c|c|c|}
\hline Variable & & $\mathbf{n}$ & SMEI & $\mathbf{n}$ & $\mathbf{P M}$ & $\mathbf{n}$ & Control & $p$-Value \\
\hline \multicolumn{9}{|c|}{ Demographics } \\
\hline \multirow[t]{2}{*}{ Sex } & Male & 75 & $12(16)$ & 194 & $22(11.3)$ & 92 & $30(32.6)$ & $<0.0001$ * \\
\hline & Female & & $63(84)$ & & $172(88.7)$ & & $62(67.4)$ & \\
\hline \multirow[t]{4}{*}{ Age } & 18 & 72 & $6(8.3)$ & 184 & $21(11.4)$ & 85 & $7(8.2)$ & 0.28 \\
\hline & 19 & & $26(36.1)$ & & $50(27.2)$ & & $32(37.6)$ & \\
\hline & 20 & & $29(40.3)$ & & $63(34.2)$ & & $28(32.9)$ & \\
\hline & $\geq 21$ & & $11(15.3)$ & & $50(27.2)$ & & $18(21.2)$ & \\
\hline \multirow[t]{4}{*}{ Race } & Caucasian only & 73 & $48(65.8)$ & 182 & $138(75.8)$ & 85 & $46(54.1)$ & $0.0022^{*,+}$ \\
\hline & African American only & & $3(4.1)$ & & $8(4.4)$ & & $12(14.1)$ & \\
\hline & Hispanic/Latino only & & $22(30.1)$ & & $36(19.8)$ & & $27(31.8)$ & \\
\hline & Other including bi-racial & & $20(24.1)$ & & $36(43.4)$ & & $27(32.5)$ & \\
\hline \multirow[t]{4}{*}{ Year } & Freshman & 74 & $8(10.8)$ & 183 & $41(22.2)$ & 92 & $17(18.5)$ & $<0.0001^{*}$ \\
\hline & Sophomore & & $48(64.9)$ & & $56(30.3)$ & & $48(52.2)$ & \\
\hline & Junior & & $13(17.6)$ & & $75(40.5)$ & & $6(6.5)$ & \\
\hline & $\geq$ Senior & & $5(6.8)$ & & $13(7.0)$ & & $21(22.8)$ & \\
\hline \multirow[t]{3}{*}{ GPA } & $3.5-4.0$ & 70 & $25(35.7)$ & 184 & $91(49.5)$ & 90 & $36(40.0)$ & 0.042 \\
\hline & $3.0-3.49$ & & $35(47.3)$ & & $71(38.6)$ & & $33(36.7)$ & \\
\hline & $\leq 2.9$ & & $10(14.3)$ & & $22(12.0)$ & & $21(23.3)$ & \\
\hline \multicolumn{9}{|c|}{ Anthropometrics } \\
\hline & Height (cm) & 72 & $166.4(8.0)$ & 194 & $166.0(7.6)$ & 92 & $167.2(9.6)$ & 0.4991 \\
\hline & Weight (kg) & 72 & $65.8(13.4)$ & 193 & $63.0(11.8)^{+}$ & 92 & $68.7(16.5)^{\dagger}$ & $0.0040 *$ \\
\hline & $\operatorname{BMI}\left(\mathrm{kg} / \mathrm{m}^{2}\right)$ & 72 & $23.6(3.7)$ & 193 & $22.8(3.6)^{\dagger}$ & 92 & $24.4(4.3)^{\dagger}$ & $0.0060 *$ \\
\hline & Waist Circumference $(\mathrm{cm})$ & 72 & $76.1(9.1)^{\ddagger}$ & 194 & $74.1(8.2)^{\dagger}$ & 92 & $80.3(13.5)^{\dagger, \ddagger}$ & $<0.0001$ * \\
\hline & Hip Circumference (cm) & 72 & $99.4(8.5)$ & 194 & $97.2(7.9)^{+}$ & 92 & $100.8(10.2)^{\dagger}$ & $0.0035^{*}$ \\
\hline & Neck Circumference $(\mathrm{cm})$ & 72 & $32.7(2.9) \ddagger$ & 194 & $32.0(2.5)^{+}$ & 92 & $34.2(3.6)^{t, \ddagger}$ & $<0.0001$ * \\
\hline & Systolic Blood Pressure (mmHg) & 72 & $112.5(13.8)$ & 194 & $110.8(11.9)$ & 92 & $109.0(11.2)$ & 0.1951 \\
\hline & Diastolic Blood Pressure (mmHg) & 72 & $70.5(8.7)$ & 194 & $68.8(7.8)$ & 92 & $68.8(8.2)$ & 0.2912 \\
\hline
\end{tabular}

Demographic data shown in frequency and percent; $\mathrm{N}(\%)$. Anthropometric data shown in means (standard deviation); ${ }^{*} p<0.05$, Chi Square analysis; ${ }^{\dagger} p<0.05$, Fisher's Exact test when cell sizes were $<5$; $p$-value, One-way analysis of variance (ANOVA) by group; ${ }^{*} p<0.05$ : $^{\dagger}$ significant differences between control and PM; ${ }^{\ddagger}$ significant differences between control and SMEI.

\section{Behavior}

\subsection{Fruit and Vegetable Intake}

Average baseline fruit and vegetable intake for SMEI, PM, and control was $3.7 \pm 2.9,3.9 \pm 2.9$ and $3.3 \pm 2.5$ servings/day, respectively (Table 2). From baseline to 12-month follow-up, fruit and vegetable consumption decreased across all groups. However, one-way ANOVA identify fruit and vegetable consumption in SMEI ( -0.14 servings) and PM ( -0.71 servings) remained stable across time while control had a significant decrease ( -1.1 servings) by $12-$ months. After transformation of the variable to improve normality, significance was found from baseline to 12-months in SMEI $(p=0.0210)$ 
and control $(p=0.0012)$ but not within PM $(p=0.3023)$. One-way ANOVA results (Table 2$)$ show significant differences among NCI FV servings between groups $(p<0.0001)$.

NCI FV null model LRT was significant $\left(\chi^{2}(1)=19.47, p<0.0001\right)$. Significant type 3 tests of fixed effects for race/ethnicity: $\mathrm{F}(3,453)=2.88, p=0.0358$. and time: $\mathrm{F}(1629)=13.05, p=0.0003$, but not with gender $(p=0.26)$, age $(p=0.60)$, or group $(p=0.19)$ (data tables not shown for model type 3 fixed effects). Fixed effects significance was indicated within time $(p=0.0002)$ and 'other' race/ethnicity $(p=0.0108)$ (Table 3$)$. No group by time interaction was detected $(p=0.26)$. After Tukey adjustment for multiple comparisons, a significant difference was seen only between PM (adj. mean $=2.5$ servings) and control groups (adj. mean $=2.3$ servings $/$ day $)(p=0.0064)$.

Table 2. One-way ANOVA of behavioral changes across time and group.

\begin{tabular}{|c|c|c|c|c|c|c|c|c|}
\hline Variable & & n & Baseline & $\mathbf{n}$ & 6-Months & $\mathbf{n}$ & 12-Months & $p$-Value ${ }^{a}$ \\
\hline \multirow{2}{*}{ NCI FV (cup servings) } & PM & 203 & $3.9(2.9)$ & 131 & $3.4(2.3) \ddagger$ & 100 & $3.1(1.9) \ddagger$ & \\
\hline & Control & 92 & $3.3(2.5)$ & 37 & $2.4(1.8) \ddagger$ & 61 & $2.2(1.6)^{\dagger, \ddagger}$ & \\
\hline \multirow[t]{2}{*}{ IPAQ (METs) } & SMEI & 74 & $\begin{array}{c}2876.3 \\
(1813.6)\end{array}$ & 34 & $\frac{3410.2}{(1704.1)^{\dagger}}$ & 36 & $\begin{array}{c}2791.2 \\
(1608.0)\end{array}$ & $0.0055 *$ \\
\hline & Control & 90 & $\begin{array}{c}2772.6 \\
(2592.6)\end{array}$ & 37 & $\begin{array}{c}2385.5 \\
(2242.3)^{\dagger}\end{array}$ & 60 & $\begin{array}{c}2830.1 \\
(2765.8)\end{array}$ & \\
\hline PSS (score 0-56) & SMEI & 70 & $23.6(8.3)^{+}$ & 32 & $21.4(6.6)^{\dagger}$ & 34 & $25.2(4.9)^{\dagger}$ & $<0.0001 *$ \\
\hline
\end{tabular}

Self-reported behavioral measurements were collected from all individuals at baseline and post intervention via survey. Untransformed baseline, 6-month, and 12-month measures reported in means and standard deviations (mean (SD)). ${ }^{a}$ Transformed variables were used for further analyses and $p$-values in table. One-way ANOVA was used to analyze the main effects of group (SMEI, PM, and C). ${ }^{*} p<0.05 ;{ }^{\dagger} p<0.05$ between SMEI and Control; $\ddagger p<0.05$ between PM and Control. NCI FV: National Cancer Institute's Fruit and Vegetable Screener; IPAQ: International Physical Activity Questionnaire; PSS: Perceived Stress Scale

Table 3. Mixed Regression Models for Behavior.

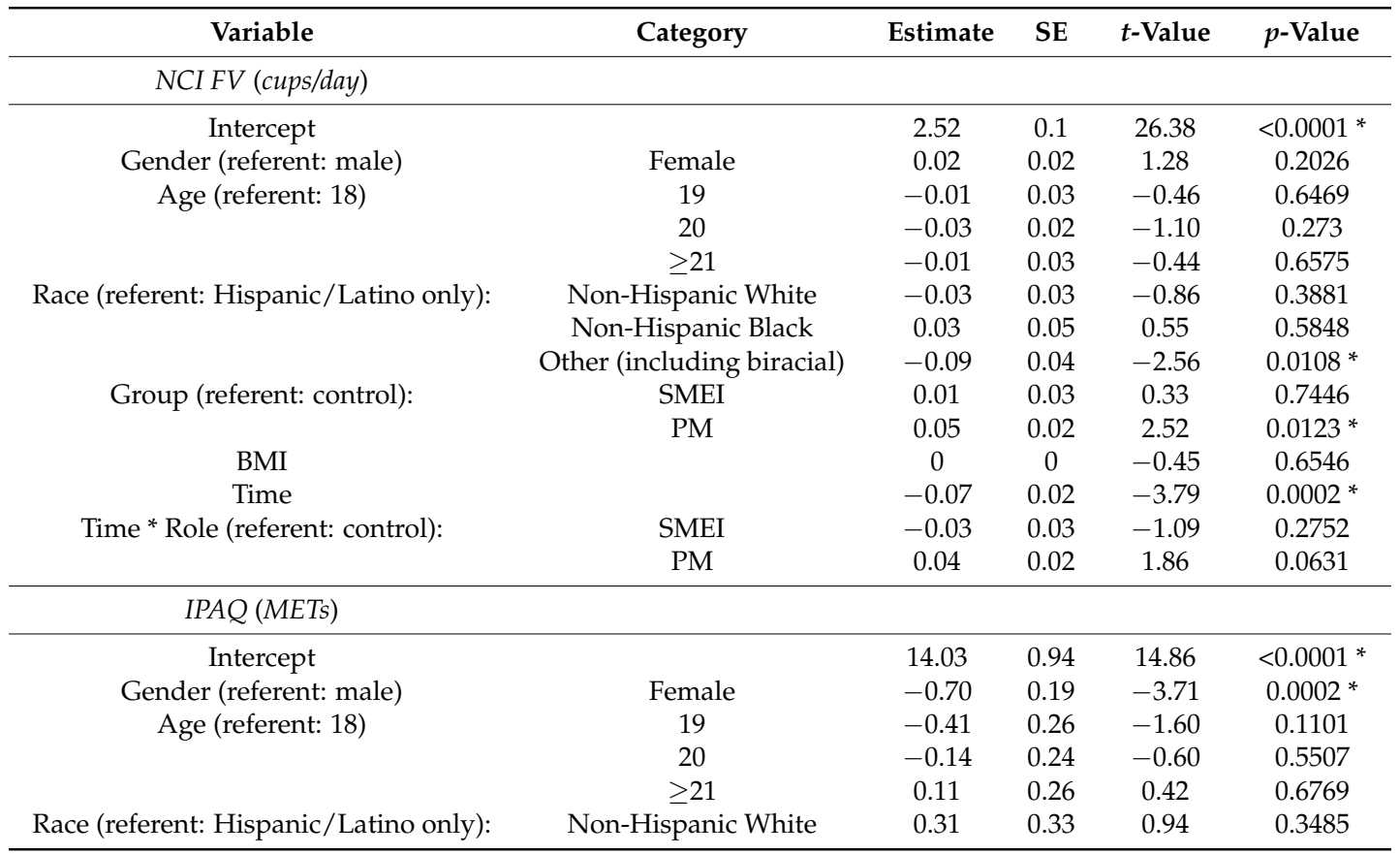


Table 3. Cont.

\begin{tabular}{|c|c|c|c|c|c|}
\hline Variable & Category & Estimate & SE & $t$-Value & $p$-Value \\
\hline \multirow{4}{*}{ Group (referent: control): } & Non-Hispanic Black & -0.10 & 0.5 & -0.20 & 0.8449 \\
\hline & Other (including biracial) & -0.14 & 0.36 & -0.38 & 0.7044 \\
\hline & SMEI & 0.64 & 0.25 & 2.61 & 0.0093 * \\
\hline & PM & 0.24 & 0.19 & 1.24 & 0.2174 \\
\hline BMI & & 0.03 & 0.04 & 0.85 & 0.3943 \\
\hline Time & & -0.01 & 0.18 & -0.05 & 0.9641 \\
\hline \multirow[t]{2}{*}{ Time ${ }^{*}$ Role (referent: control): } & SMEI & 0.06 & 0.26 & 0.24 & 0.8108 \\
\hline & PM & -0.02 & 0.21 & -0.09 & 0.9269 \\
\hline \multicolumn{6}{|l|}{ PSS (score 0-56) } \\
\hline \multirow{7}{*}{ Race (referent: Hispanic/Latino only): } & & 24.13 & 2 & 12.07 & $<0.0000 *$ \\
\hline & Female & 0.95 & 0.4 & 2.38 & $0.0177 *$ \\
\hline & 19 & 1.62 & 0.53 & 3.06 & $0.0023 *$ \\
\hline & 20 & -0.82 & 0.49 & -1.67 & 0.0945 \\
\hline & $\geq 21$ & -1.48 & 0.53 & -2.77 & $0.0059 *$ \\
\hline & Non-Hispanic White & -1.57 & 0.67 & -2.34 & $0.0194 *$ \\
\hline & Non-Hispanic Black & -1.07 & 1.05 & -1.02 & 0.3068 \\
\hline \multirow{3}{*}{ Group (referent: control): } & Other (including biracial) & -0.13 & 0.73 & -0.17 & 0.8616 \\
\hline & SMEI & -1.23 & 0.52 & -2.35 & $0.0192 *$ \\
\hline & PM & -1.63 & 0.41 & -3.93 & $0.0001 *$ \\
\hline BMI & & 0.02 & 0.08 & 0.3 & 0.7631 \\
\hline Time & & 0.97 & 0.36 & 2.66 & $0.0080 *$ \\
\hline \multirow[t]{2}{*}{ Time * Role (referent: control): } & SMEI & 0.22 & 0.53 & 0.42 & 0.6758 \\
\hline & PM & 0.51 & 0.42 & 1.22 & 0.2214 \\
\hline
\end{tabular}

Linear Mixed Model adjusted for age, gender, and race/ethnicity were used to analyze the main effects of group (SMEI, PM, and C), time, and their interaction on each behavior tool. Significant effects were followed by multiple comparisons using Tukey adjustment. $p$-values for the main effects and interaction are indicated. ${ }^{*} p<0.05$. METs: metabolic equivalency tasks in minutes/week.

\subsection{Physical Activity}

Baseline IPAQ scores for SMEI, PM, and control were 2876 METs, 2907 METs, and 3058 METs, respectively (Table 2). After a large increase in SMEI IPAQ scores at 6-month assessments, all groups IPAQ scores remained relatively the same from baseline to 12-month assessment. One-way ANOVA results (Table 2) significant differences among IPAQ METs between groups $(p=0.0055)$.

IPAQ null model LRT was significant $\left(\chi^{2}(5)=30.79, p<0.0001\right)$. Significant type 3 tests of fixed effects for gender: $\mathrm{F}(1,444)=12.02, p=0.0006$, and group: $\mathrm{F}(2503)=3.95, p=0.0199$, but not with age $(p=0.33)$, race/ethnicity $(p=0.66)$, or time $(p=0.81)$. No group by time interaction was detected $(p=0.92)$. Table 3 indicates significance between gender $(p=0.0002)$ and SMEI $(p=0.0093)$. After Tukey adjustment for multiple comparisons, SMEI (adj. mean $=14.8$ ) also had significantly higher IPAQ score than control (adj. mean $=13.7)(p=0.0013)$. Further, males (adj. mean $=15.38$ METs) had higher IPAQ scores than females (adj. mean $=14.15$ METs $)(p=0.0002)$.

\subsection{Perceived Stress}

Baseline averages of PSS for SMEI, PM, and control were 23.6, 22.7, and 27.6, respectively (Table 2). Control participants PSS was higher at baseline and remained higher across all time points. One-way ANOVA results (Table 2) significant differences among PSS between groups $(p<0.0001)$.

PSS null model LRT was significant $\left(\chi^{2}(1)=27.66, p<0.0001\right)$. Significant type 3 tests of fixed effects for gender: $\mathrm{F}(1,482)=6.09, p=0.0139$, age: $\mathrm{F}(3614)=6.62, p=0.0002$, group: $\mathrm{F}(2,576)=16.92$, $p \leq 0.0001$, time: $\mathrm{F}(1584)=5.79, p=0.0164$, and approaching significance for race/ethnicity: $\mathrm{F}(3,457)$ $=2.51, p=0.0581$. No group by time interaction was detected $(p=0.25)$. After Tukey comparison test, PM $($ mean $=22.93)$ had a better PSS than control $($ mean $=27.04)(p=0.0001)$ and SMEI $($ mean $=23.43)$ had a better PSS than control $(p=0.0192)$. Further, males (mean $=23.04)$ had a better PSS than females $($ mean $=24.22)(p=0.0177)$. 


\section{Discussion}

The aim of the present study was to investigate health behavior changes among college student research partners in a CBPR healthy lifestyle intervention compared to control students who were not engaged in the intervention's design and implementation. The intervention groups (SMEI and PM) started with and maintained healthier lifestyle habits compared with the control group throughout the year-long study. On average, while all groups showed reductions in fruit and vegetable consumption across the 12 months, the control group demonstrated the largest decrease. Similarly, the intervention groups reported higher activity and lower stress scores than the control group.

The American College Health Association-National College Health Association (ACHA-NCHA) 2016 survey reports the majority of undergraduate students in the United States are only consuming $1-2$ servings of fruits and vegetables per day (61\% were getting $1-2$ servings per day, $27 \%$ were getting 3-4 serving per day) [37]. Although the student partners enrolled in the Get Fruved study did not meet recommended daily intake of fruits and vegetables (2015-2020 Dietary Guidelines for Americans and the United States Department of Agricultures' MyPlate recommends five servings of fruit and vegetables per day for a healthy balanced diet $[38,39])$, their average intake was higher than the national average at completion of the intervention in both SMEI ( 3.6 servings) and PM (3.1 servings) groups. More specifically, in fruit and vegetable cup servings per day, we identified a decline in servings across the year in PM (baseline 3.9 cup servings per day; after 12 months 3.1 cup servings per day) and SMEI (baseline 3.7 cup servings per day; after 12 months 3.6 cup servings per day) students that was less than that of their control (baseline 3.3 cup servings per day; after 12 months 2.2 cup servings per day) counterparts. Further analysis via LMM analysis identified, after Tukey adjustment, PM had significantly higher FV servings compared to control, in relation to time.

Decreased physical activity has been linked to numerous medical conditions, including cardiometabolic disease such as cardiovascular disease and diabetes [40]. Despite this link, only 50\% of USA adults meet physical activity recommendations of $150 \mathrm{~min}$ per week of moderate-vigorous activity [41-43] and college students, in particular, engage in aerobic exercise less than 3 times per week [44]. In terms of IPAQs MET minutes per week, the recommended 150 min of moderate to vigorous physical activity per week is equal to the range of 500-1000 METs (depending on intensity) [43]. In the present study, participants averaged over 2000 MET minutes per week at all time points, indicating they met physical activity recommendations throughout the duration of the study. LMM analysis showed both PM and SMEI had greater activity levels than control in relation to time. Further, males had higher activity than females which his supported by previous findings $[45,46]$.

In contrast to Bieter, et al. who identified transfer students, upperclassmen, and those living off-campus to be the students with the highest self-reported stress levels [47], the present study found students 19 years of age to have higher stress levels than the older students. Using Cohen's PSS, Civitci determined the mean stress score of an average college student was 30.4 [48]. In the present study, both intervention groups, as well as the control group, reported mean stress scores from 21.2-27.6 across all time points. However, we do acknowledge that average PSS was higher at 12 months than baseline but could be attributed to 12-month assessments being taken near university final exams. Further LMM analysis showed both PM and SMEI had significantly lower stress scores than control, males lower than females, and Non-Hispanic White participants lower than Non-Hispanic Black and Other (including biracial). These results suggest students in the present study may have been better at managing their stress than the average college student due to a selection bias of individuals who volunteered to participate. Previous literature has shown that racial minorities experience higher stress and females feel more academic pressure, which increases stress, despite reporting higher levels of support from family and friends compared to males [49-51]. However, although our population was largely female, ethnicity was predominately Caucasian, as well as having students enrolled that are interested in health and designing a health intervention for their peers. 
When examining specific studies who observe CBPR based student partners, limited information is available on health behaviors among partners who are developing and engaging in intervention dissemination.

Some limitations are found within this study. First, we did find some drop-out among groups at each time point. This may be due to time, location on campus, or subsequent drop out from college. Second, our cohort was relatively healthy at baseline: they met physical activity recommendations and had higher fruit and vegetable consumption and lower stress levels than average college students. Therefore, they were less likely to make significant behavior improvements across this one-year period. This limitation is attributed to selection bias as students interested in participating in a CBPR healthy lifestyle research study were likely to be practice healthy lifestyle choices at baseline. Likewise, though, control students were recruited to be a control student in a health intervention, give anthropometric and behavior data, and knew the program. This allowed for a more comparable sample of cohorts between intervention and control groups. Had student participants been more reflective of a general college population, efforts to improve healthy lifestyle behaviors may have elicited more substantial changes. However, the aim of the overall study was to successfully implement a healthy lifestyle CBPR which students enrolled would be interested in healthy living. We recognize this as a limitation because findings are not generalizable to the average college population, specifically the large population of students who are not interested and do not prioritize healthy lifestyle behaviors and the promotion of such lifestyles. Furthermore, control students began a baseline with a higher BMI and waist circumference. This placed them at a disadvantage to those in the intervention groups and future studies warrant intervention and control anthropometrically matched groups for comparison.

Several studies have used college students to gain insight into a collegiate population, develop and/or implement an intervention, or to assist with data collection [2-5,7-10,12-18,24] but to the best of our knowledge, ours is the first to examine changes among college student research partners in a CBPR healthy lifestyle intervention compared to control students who were not engaged in the intervention's design and implementation.

\section{Conclusions}

In this reasonably healthy group of students, health behaviors remained relatively stable across group and time during the 12 months, specifically in intervention groups. Specifically, we found fruit and vegetable consumption slightly declined, along with moderately higher perceived stress and stable physical activity. With these moderate changes across this year pilot intervention, it leads us to believe that being part of the design and implementation of a peer-led, health promotion intervention helped these students sustain their healthy behaviors over the year and attenuated a decline seen within control subjects and among typical college student populations.

Author Contributions: Conceptualization, S.E.C., A.E.M., K.K.K. and M.D.O.; Data curation, M.B., S.E.C., K.R., K.L. and M.J.V.; Formal analysis, M.B.; Funding acquisition, S.E.C., A.E.M., K.K.K. and M.D.O.; Investigation, M.B., S.E.C., K.R., K.L., A.E.M., M.J.V., K.K.K. and M.D.O.; Methodology, M.B., S.E.C., A.E.M., K.K.K. and M.D.O.; Project administration, M.B., S.E.C., A.E.M., M.J.V., K.K.K. and M.D.O.; Resources, S.E.C., A.E.M., K.K.K. and M.D.O.; Software, M.D.O.; Supervision, S.E.C., A.E.M., K.K.K. and M.D.O.; Visualization, S.E.C.; Writing-original draft, M.B.; Writing—review \& editing, M.B., S.E.C., K.R., K.L., A.E.M., M.J.V., K.K.K. and M.D.O.

Funding: This project was supported by Agriculture and Food Research Initiative Grant no. 2014-67001-21851 from the USDA National Institute of Food and Agriculture, "Get Fruved:" A peer-led, train-the-trainer social marketing intervention to increase fruit and vegetable intake and prevent childhood obesity-A2101 and West Virginia University Experimental Station Hatch WVA00627 and WVA00641.

Acknowledgments: We would like to thank the engagement and involvement of the research participants. Further we would like to lank our multistate partners from the Healthy Campus Research Consortium.

Conflicts of Interest: The authors declare no conflict of interest.

Ethics Approval and Consent to Participate: All procedures were reviewed and approved from each university's Internal Review Board: West Virginia University: 1409447372, University of Tennessee: 9366B, University of Maine: 2014-06-21, Syracuse University: 14-175, University of Florida: 2014-U-0547FRUVED, Kansas State University: 
7257, Auburn University: 15-164EP1504, and South Dakota State University: 1414023EXP. Informed consent was collected from each participant prior to enrollment.

Availability of Data and Materials: The datasets used and analyzed during the current study are available from the corresponding author on reasonable request.

$\begin{array}{ll}\text { Abbreviations } & \\ \text { CBPR } & \text { Community-Based Participatory Research } \\ \text { SMEI } & \text { Social Marketing and Environmental Intervention } \\ \text { PM } & \text { Peer Mentors for Health } \\ \text { NCI FV } & \text { National Cancer Institute's Fruit and Vegetable Screener } \\ \text { IPAQ } & \text { International Physical Activity Questionnaire } \\ \text { PSS } & \text { Cohen's Perceived Stress Scale } \\ \text { METs } & \text { Metabolic Equivalency Tasks-minutes/week } \\ \text { AIC } & \text { Akaike Information Criterion } \\ \text { LRT } & \text { Likelihood Ratio chi-squared test } \\ \text { AR1 } & \text { Autoregressive } \\ \text { ACHA-NCHA } & \text { American College Health Association-National College Health Association }\end{array}$

\section{References}

1. Salimi, Y.; Shahandeh, K.; Malekafzali, H.; Loori, N.; Kheiltash, A.; Jamshidi, E.; Frouzan, A.S.; Majdzadeh, R. Is community-based participatory research (CBPR) useful? A systematic review on papers in a decade. Int. J. Prev. Med. 2012, 3, 386-393. [PubMed]

2. Jacquez, F.; Vaughn, L.M.; Wagner, E. Youth as Partners, Participants or Passive Recipients: A Review of Children and Adolescents in Community-Based Participatory Research (CBPR). Am. J. Community Psychol. 2013, 51, 176-189. [CrossRef] [PubMed]

3. Meininger, J.C.; Reyes, L.R.; Selwyn, B.J.; Upchurch, S.L.; Brosnan, C.A.; Taylor, W.C.; Villagomez, E.; Quintana, V.; Pullis, B.; Caudill, D.; et al. A Structured, Interactive Method for Youth Participation in a School District-University Partnership to Prevent Obesity. J. Sch. Health 2010, 80, 493-500. [CrossRef] [PubMed]

4. Burkhart, R. Urban Indian voices: A community-based participatory research health and needs assessment. Am. Indian Alaska Native Ment. Health Res. 2010, 17, 49.

5. Brown, L.D.; Redelfs, A.H.; Taylor, T.J.; Messer, R.L. Comparing the functioning of youth and adult partnerships for health promotion. Am. J. Community Psychol. 2015, 56, 25-35. [CrossRef] [PubMed]

6. Wallerstein, N.; Duran, B. The conceptual, historical, and practice roots of community based participatory research and related participatory traditions. In Community Based Participatory Research for Health; Jossey Bass: San Francisco, CA, USA, 2003; Chapter 2; pp. 27-52.

7. Trinidad, A.M. Toward kuleana (responsibility): A case study of a contextually grounded intervention for Native Hawaiian youth and young adults. Aggress. Violent Behav. 2009, 14, 488-498. [CrossRef] [PubMed]

8. Peterson, T.H.; Dolan, T.; Hanft, S. Partnering with youth organizers to prevent violence: An analysis of relationships, power, and change. Prog. Community Health Partnersh. 2010, 4, 235-242. [CrossRef] [PubMed]

9. Noone, J.; Sullivan, M.; McKinnis, N.C.; Allen, T.L.; Regalado, C.; Esqueda, T. Latino youth participation in community-based participatory research to reduce teen pregnancy disparities. Child. Youth Serv. Rev. 2016, 63, 36-39. [CrossRef]

10. Mooney-Somers, J.; Erick, W.; Scott, R.; Akee, A.; Kaldor, J.; Maher, L. Enhancing Aboriginal and Torres Strait Islander young people's resilience to blood-borne and sexually transmitted infections: Findings from a community-based participatory research project. Health Promot. J. Aust. 2009, 20, 195-201. [CrossRef]

11. Minkler, M.; Wallerstein, N. Community-Based Participatory Research for Health: From Process to Outcomes; John Wiley \& Sons: New York, NY, USA, 2011.

12. Mendenhall, T.; Whipple, H.; Harper, P.; Haas, S. Students Against Nicotine and Tobacco Addiction (SANTA): Community-based participatory research in a high-risk young adult population. Fam. Syst. Health 2008, 26, 225. [CrossRef] 
13. Mance, G.A.; Mendelson, T.; Byrd, B.; Jones, J.; Tandon, D. Utilizing community-based participatory research to adapt a mental health intervention for African American emerging adults. Prog. Community Health Partnersh. 2010, 4, 131-140. [CrossRef] [PubMed]

14. Israel, B.A.; Schulz, A.J.; Parker, E.A.; Becker, A.B.; Community-Campus Partnerships for Health. Community-based participatory research: Policy recommendations for promoting a partnership approach in health research. Educ. Health 2001, 14, 182-197.

15. Gibson, J.E.; PFlaspohler, D.; Watts, V. Engaging youth in bullying prevention through community-based participatory research. Fam. Community Health 2015, 38, 120-130. [CrossRef] [PubMed]

16. Diamond, S.; Schensul, J.J.; Snyder, L.B.; Bermudez, A.; D'Alessandro, N.; Morgan, D.S. Building Xperience: A multilevel alcohol and drug prevention intervention. Am. J. Community Psychol. 2009, 43, $292-312$. [CrossRef] [PubMed]

17. Christiansen, E.D. Adolescent Cape Verdean girls' experiences of violence, incarceration, and deportation: Developing resources through participatory community-based groups. Int. J. Intercult. Relat. 2010, 34, 127-140. [CrossRef]

18. Bogart, L.M.; Elliott, M.N.; Uyeda, K.; Hawes-Dawson, J.; Klein, D.J.; Schuster, M.A. Preliminary healthy eating outcomes of SNaX, a pilot community-based intervention for adolescents. J. Adolesc. Health 2011, 48, 196-202. [CrossRef] [PubMed]

19. Greaney, M.L.; Less, F.D.; White, A.A.; Dayton, S.F.; Riebe, D.; Blissmer, B.; Shoff, S.; Walsh, J.R.; Greene, G.W. College Students' Barriers and Enablers for Healthful Weight Management: A Qualitative Study. J. Nutr. Educ. Behav. 2009, 41, 281-286. [CrossRef] [PubMed]

20. Jones, B.D.; Cunningham-Williams, R.M. Hookah and Cigarette Smoking among African American College Students: Implications for Campus Risk Reduction and Health Promotion Efforts. J. Am. Coll. Health 2016, 64, 309-317. [CrossRef] [PubMed]

21. Mackert, M.; Lazard, A.; Guadagno, M.; Hughes Wagner, J. The role of implied motion in engaging audiences for health promotion: Encouraging naps on a college campus. J. Am. Coll. Health 2014, 62, 542-551. [CrossRef] [PubMed]

22. Pelletier, J.E.; Lytle, L.A.; Laska, M.N. Stress, health risk behaviors, and weight status among community college students. Health Educ. Behav. 2016, 43, 139-144. [CrossRef] [PubMed]

23. Quick, V.; Byrd-Bredbenner, C.; White, A.A.; Brown, O.; Colby, S.; Shoff, S.; Lohse, B.; Horacek, T.; Kidd, T.; Greene, G. Eat, sleep, work, play: Associations of weight status and health-related behaviors among young adult college students. Am. J. Health Promot. 2014, 29, e64-e72. [CrossRef] [PubMed]

24. Boyle, J.; Mattern, C.O.; Lassiter, J.W.; Ritzler, J.A. Peer 2 peer: Efficacy of a course-based peer education intervention to increase physical activity among college students. J. Am. Coll. Health 2011, 59, 519-529. [CrossRef] [PubMed]

25. Vadeboncoeur, C.; Townsend, N.; Foster, C. A meta-analysis of weight gain in first year university students: Is freshman 15 a myth? BMC Obes. 2015, 2, 22. [CrossRef] [PubMed]

26. Barr, M.L.; Olfert, M.D.; Zhou, W.; Riggsbee, K.; Mathews, A.E.W.; Vilaro, M.; Kattelmann, K.K.; Andrea, H.; White, A.; Horacek, T.; et al. Recruitment Strategies Implemented across a Four-State Lifestyle Intervention: Get Fruved Study. FASEB J. 2016, 30 (Suppl. 3), 674-737.

27. Olfert, M.; Barr, M.L.; Riggsbee, K.; Kattelmann, K.K.; Leischner, K.; Mathews, A.E.; Vilaro, M.; Colby, S.E. A Community Based Participatory Approach to Training Young Adults to Design and Implement a Social Marketing Framed Lifestyle Intervention on Their College Campus. Educ. Sci. 2018, 8, 150. [CrossRef]

28. Krieger, N.; Sidney, S. Racial discrimination and blood pressure: The CARDIA Study of young black and white adults. Am. J. Public Health 1996, 86, 1370-1378. [CrossRef] [PubMed]

29. Muntner, P.; Lewis, C.E.; Diaz, K.M.; Carson, A.P.; Kim, Y.; Calhoun, D.; Yano, Y.; Viera, A.J.; Shimbo, D. Racial Differences in Abnormal Ambulatory Blood Pressure Monitoring Measures: Results From the Coronary Artery Risk Development in Young Adults (CARDIA) Study. Am. J. Hypertens. 2015, 28, 640-648. [CrossRef] [PubMed]

30. National Cancer Institute (NCI) Scoring the All-Day Screener. 2017. Available online: https:/ / epi.grants. cancer.gov/diet/screeners/fruitveg/scoring/allday.html (accessed on 19 October 2018).

31. Booth, M. Assessment of physical activity: An international perspective. Res. Q. Exerc. Sport 2000, 71 (Suppl. S2), 114-120. [CrossRef] [PubMed] 
32. Cohen, S.; Kamarck, T.; Mermelstein, R. A global measure of perceived stress. J. Health Soc. Behav. 1983, 24, 385-396. [CrossRef] [PubMed]

33. SAS Institutue Inc. Base SAS®9.3 Procedures Guide [Computer Program]; SAS Institute Inc.: Cary, NC, USA, 2011.

34. JMP Pro, v10; SAS: Cary, NC, USA, 2012.

35. Wolfinger, R.; Chang, M. Comparing the SAS GLM and MIXED Procedures for Repeated Measures; SAS Institute Inc.: Cary, NC, USA, 1998.

36. Hamer, R.M.; Simpson, P.M. An introduction to the analysis of repeated measures for continuous response data using PROC GLM and PROC MIXED. In Proceedings of the Annual Meeting of the SAS Users Group International, Nashville, TN, USA, 22 March 1998.

37. American College Health Association. American College Health Association-National College Health Assessment II: Reference Group Executive Summary Spring 2016; American College Health Association: Hanover, MD, USA, 2016.

38. USDA. Choose MyPlate. 2017. Available online: https://www.choosemyplate.gov/ (accessed on 19 October 2018).

39. Office of Disease Prevention and Health Promotion. 2015-2020 Dietary Guidelines for Americans-Health.gov. 2017. Available online: https:/ / health.gov/dietaryguidelines/2015/ (accessed on 19 October 2018).

40. Church, T.S. Invited Commentary: Little Steps Lead to Huge Steps-It's Time to Make Physical Inactivity Our Number 1 Public Health Enemy. Am. J. Epidemiol. 2016, 184, 633-635. [CrossRef] [PubMed]

41. Center for Disease Control and Prevention. Recommendations \& Guidelines I Physical Activity I CDC. 2017. Available online: https:/ / www.cdc.gov/physicalactivity/resources/recommendations.html (accessed on 19 October 2018).

42. Center for Disease Control and Prevention. National Center for Chronc Disease Prevention and Health Promotion, Division of Nutrition, Physical Activity, and Obesity. Data, Trend and Maps. 2017. Available online: https://nccd.cdc.gov/dnpao_dtm/rdPage.aspx?rdReport=DNPAO_DTM. ExploreByTopic\&islClass=PA\&islTopic=PA1\&go=GO (accessed on 19 October 2018).

43. Office of Disease Prevention and Health Promotion. Appendix 1-2008 Physical Activity Guidelines-Health.gov. 2017. Available online: https://health.gov/paguidelines/guidelines/appendix1.aspx (accessed on 19 October 2018).

44. Huang, T.T.-K.; Harris, K.J.; Lee, R.E.; Nazir, N.; Born, W.; Kaur, H. Assessing overweight, obesity, diet, and physical activity in college students. J. Am. Coll. Health 2003, 52, 83-86. [CrossRef] [PubMed]

45. Choi, J.Y.; Chang, A.K.; Choi, E.-J. Sex differences in social cognitive factors and physical activity in Korean college students. J. Phys. Ther. Sci. 2015, 27, 1659-1664. [CrossRef] [PubMed]

46. Azevedo, M.R.; Araújo, C.L.; Reichert, F.F.; Siqueira, F.V.; da Silva, M.C.; Hallal, P.C. Gender differences in leisure-time physical activity. Int. J. Public Health 2007, 52, 8-15. [CrossRef] [PubMed]

47. Beiter, R.; Nash, R.; McCrady, M.; Rhoades, D.; Linscomb, M.; Clarahan, M.; Sammut, S. The prevalence and correlates of depression, anxiety, and stress in a sample of college students. J. Affect. Disord. 2015, 173, 90-96. [CrossRef] [PubMed]

48. Civitci, A. Perceived Stress and Life Satisfaction in College Students: Belonging and Extracurricular Participation as Moderators-ScienceDirect. 2017. Available online: http:/ /www.sciencedirect.com/science/ article/pii/S1877042815050958 (accessed on 19 October 2018).

49. Rayle, A.D.; Chung, K.-Y. Revisiting first-year college students' mattering: Social support, academic stress, and the mattering experience. J. Coll. Stud. Retent. 2007, 9, 21-37. [CrossRef]

50. Johnson, D.R.; Wasserman, T.H.; Yildirim, N.; Yonai, B.A. Examining the Effects of Stress and Campus Climate on the Persistence of Students of Color and White Students: An Application of Bean and Eaton's Psychological Model of Retention. Res. High. Educ. 2014, 55, 75-100. [CrossRef]

51. Albright, J.N.; Hurd, N.M. Constellations of social support among underrepresented college students: Associations with mental health. Appl. Dev. Sci. 2018, 22, 258-269. [CrossRef]

(C) 2018 by the authors. Licensee MDPI, Basel, Switzerland. This article is an open access article distributed under the terms and conditions of the Creative Commons Attribution (CC BY) license (http:/ / creativecommons.org/licenses/by/4.0/). 